\title{
Optimum sizing of offshore wind farm export cables
}

\author{
Pérez-Rúa, Juan-Andrés; Das, Kaushik; Cutululis, Nicolaos Antonio
}

Published in:

International Journal of Electrical Power and Energy Systems

Link to article, DOI:

10.1016/j.ijepes.2019.06.026

Publication date:

2019

Document Version

Peer reviewed version

Link back to DTU Orbit

Citation (APA):

Pérez-Rúa, J-A., Das, K., \& Cutululis, N. A. (2019). Optimum sizing of offshore wind farm export cables. International Journal of Electrical Power and Energy Systems, 113, 982-990.

https://doi.org/10.1016/j.ijepes.2019.06.026

\section{General rights}

Copyright and moral rights for the publications made accessible in the public portal are retained by the authors and/or other copyright owners and it is a condition of accessing publications that users recognise and abide by the legal requirements associated with these rights.

- Users may download and print one copy of any publication from the public portal for the purpose of private study or research.

- You may not further distribute the material or use it for any profit-making activity or commercial gain

- You may freely distribute the URL identifying the publication in the public portal

If you believe that this document breaches copyright please contact us providing details, and we will remove access to the work immediately and investigate your claim. 


\title{
Optimum Sizing of Offshore Wind Farm Export Cables
}

\author{
Juan-Andrés Pérez-Rúa, Kaushik Das, and Nicolaos A. Cutululis
}

\begin{abstract}
A methodology for optimum sizing of offshore wind farms high voltage $\mathrm{AC}$ export cables is presented. The method uses as main input site-dependent time series of wind power generation and seabed temperature, in order to apply Dynamic Temperature Estimation (DTE) analysis using a Thermo-Electrical Equivalent model (TEE), followed by an estimation of loss-of-life fractions in the insulation materials through a probabilistic lifetime model, known as Arrhenius-IPM. The lifetime estimation takes into consideration the effects of cable total length: the high capacitive currents and the statistical volume enlargement law. Furthermore, the cable lifetime is inferred based on the accumulated ageing effects previously quantified. The methodology is embedded in an optimization framework which provides a transparent, flexible, and scalable formulation. Finally, the applicability of the method is illustrated through a case study, complemented with a sensitivity analysis targeting the main parameters. Results show that a reduction of the objective function of around $5 \%$ is achieved when using the proposed methodology.
\end{abstract}

Index Terms-Offshore wind energy, AC transmission cables, Optimization, Dynamic temperature estimation, Electro-thermal stress, Probabilistic lifetime estimation.

\section{NOMENCLATURE}

$\alpha_{0} \quad$ Scale factor of the pdf for lifetime model for $E=E_{0}$ and $\theta_{i_{t}}=\theta_{0}$

$\alpha_{t}\left(E, \theta_{i_{j_{t}}}\right)$ Scale factor of the pdf for lifetime model for a given $E$ and $\theta_{i_{t}}$

$\beta_{t} \quad$ Shape parameter of the pdf for lifetime model

$T_{\boldsymbol{c}} \quad$ Set of cables available

$\lambda_{1}+\lambda_{2}$ Ratio of screen and armouring losses respect to joule losses

$\rho_{t h} \quad$ Soil thermal resistivity

$\theta_{0} \quad$ Room reference temperature for lifetime model

$\theta_{n} \quad$ Industrial continuous rated temperature

$\theta_{i_{\text {peak }}}$ Non-negative continuous variable. Models the calculated maximum instantaneous temperature for cable $t$ in the cycle $i$

$\theta_{\text {peak }}$ Allowed maximum instantaneous conductor temperature

$A_{p_{t}} \quad$ First cost coefficient of cable $t$

$B \quad$ Parameter for lifetime model

$b \quad$ Parameter linking the synergism between electric and thermal stress for lifetime model

$b_{d} \quad$ Length of buried depth

$B_{p_{t}} \quad$ Second cost coefficient of cable $t$

$C_{p_{t}} \quad$ Third cost coefficient of cable $t$

Juan-Andrés Pérez-Rúa, Kaushik Das, and Nicolaos A. Cutululis are with the Department of Wind Energy of the Technical University of Denmark, Frederiksborgvej 399, 4000 Roskilde, Denmark (e-mail: juru@dtu.dk)

Manuscript received XXX, XXX; revised XXX, XXX. $c_{t h} \quad$ Soil specific heat

$C_{t} \quad$ Cost per unit of length of cable $t$

$D \quad$ Enlargement factor

d Export cable total length

$d_{\text {des }} \quad$ Design length

E Electric field applied to the cable

$E_{0} \quad$ Electric field value below which electric aging is negligible

$E_{n} \quad$ Industrial continuous rated electric field

$E_{i_{n e t_{t}}}$ Net produced energy for year $i$ using cable type $t$

$F_{p_{\text {des }}}$ Design failure probability

$h \quad$ Number slot-hours in the cycle $i$

$i \quad$ Annual cycle

$j \quad$ Slot-hour belonging to set $i$

$l \quad$ A physical section of the cable under analysis

$l_{D} \quad$ Real-size cable length

$l_{f} \quad$ Specimen cable length

$l_{D_{T}} \quad$ Total number of sections to divide the cable under analysis

$L T_{\text {des }}$ Design life

$L T_{i_{P_{\text {inct }}}}$ Non-negative continous variable. Models the calculated cable lifetime for $t$ in the cycle $i$

$N \quad$ Number of sub-layers for dividing the seabed layer of buried depth for thermal model

$n_{0} \quad$ Voltage Endurance Coefficient (VEC) for lifetime model

$N_{y} \quad$ Project lifetime

$P_{D} \quad$ Failure probability for real-size cables

$P_{f} \quad$ Failure probability for specimen cables

$P_{i_{\text {inct }}}$ Non-negative continuous variable. Models power increase respect to $P_{I E C_{t}}$ for cable $t$ in the cycle $i$

$P_{I E C_{t}}$ Rated power according to IEC standard for cable $t$

$P_{\text {lim }}$ Surge impedance power limit for cable $t$

$P_{\text {owf }}$ Offshore Wind Farm installed power

pf Wind farm aggregated power factor

$r \quad$ Interest rate

$r_{D} \quad$ Radius of real-size cable conductor

$r_{f} \quad$ Radius of specimen cable conductor

$R_{c_{t}}(l, j)$ Phase conductor resistance for cable $t$ section $l$ at time $j$

$s \quad$ Length of phase spacing

$S_{n_{t}} \quad$ Nominal power of cable $t$

$t \quad$ Cable type

$T L_{i_{t}} \quad$ Total electrical power losses for cable $t$ in year $i$

$V_{n} \quad$ Export system nominal voltage

$W_{d_{t}} \quad$ Total phase dielectric losses for cable $t$

$x_{i t} \quad$ Binary variable. Models whether cable $t$ is selected for cycle $i$ or not 
y Number of cycles under consideration

$\Theta_{i_{t}} \quad$ Set of calculated instantaneous conductor temperature time series for cable $t$ in the cycle $i$

$\boldsymbol{P}_{i} \quad$ Set of offshore wind power time series for cycle $i$

$\boldsymbol{T}_{i} \quad$ Set of seabed surface temperature time series for cycle $i$

$\boldsymbol{T}$ Set of seabed surface temperature time series including whole annual dataset

$I_{t}(l, j)$ Phase current through cable $t$ section $l$ at time $j$

$L_{D}\left(E, \theta_{i_{j_{t}}}, P_{D}\right)$ Time-to-failure for a given $E, \theta_{i_{j_{t}}}$, and $P_{f}$ for real-size cables

$L_{P_{f}}\left(E, \theta_{i_{j_{t}}}, P_{f}\right)$ Time-to-failure for a given $E, \theta_{i_{j_{t}}}$, and $P_{f}$ for specimen cables

\section{INTRODUCTION}

A MONG the different technologies for power production using renewable resources, offshore wind energy is shaping up as one of the fastest and most steadily growing type. The share of offshore wind has increased almost five times in the last seven year [1], reaching a globally installed power of nearly $19 \mathrm{GW}$. Offshore Wind Farms (OWFs) projects are capital intensive, having large values of operating leverage; the required electrical infrastructure costs can raise up to $15 \%$ compared to the total system costs [2]. The export cables are the power system component in charge of bringing to shore the power produced, it can have a significant impact on the overall wind farm availability being a possible single point of failure [3]. At the same time, the increasingly longer distance from shore means more $\mathrm{km}$ of export cables, raising its share in the overall project economy.

Traditionally, the sizing of offshore export cables has been done based on the CIGRÉ [4] and IEC [5]- [6] standards. The standards approach this with a classic point of view, considering steady state conditions under constant rated operation. Recently, a new approach as described in [7], consisting in worst case equivalent step-wise load profiles, is being increasingly used in the industry. This represents a strategy to minimize the cable' cross section, going towards a more refined, realistic, and simplified approach. Cables' most critical element is the insulation layer, which according to manufacturers, has an associated lifetime with failure probability, that is described in terms of rated temperature, $\theta_{n}=90^{\circ} \mathrm{C}$, and rated electric field $E_{n}$; since this material is in close contact to the conductor external layer, the conductor continuous temperature and electric field, under operation, must be fixed to $\theta_{n}$ and $E_{n}$, respectively.

There may be other factors fatiguing the cable, such as mechanical and environmental stress [8]. The former is present during manufacturing, assembling, and laying processes, but their impact is minimized considerably by following state-ofthe-art techniques throughout each process. The latter is caused by oxidation, radiation, and moisture; however submarine cables are implicitly protected against these threats, partly due to the buried depth, and partly due to the mechanical protective inner layers of the cable itself. Therefore, the simultaneous electro-thermal stress represents the main ageing factor of the insulation, and consequently, of the whole cable.
To the best of the author's research, offline lifetime estimations of OWFs cables, embedded in a holistic optimization framework, has not yet been addressed in the scientific literature. Most of the works focus on: i) conductor temperature estimation, ii) sizing cables considering a maximum instantaneous temperature never higher than $90^{\circ} \mathrm{C}$, and iii) calculation of conservative step-wise cyclic load profiles. No exploration on this component lifetime, for optimum sizing, under real dynamic operating conditions has been identified. Regarding the first topic, a calculation tool for estimating the conductor temperature time series, using a Single Core Equivalent Thermal Model (SCETM), while analyzing the impact on different cables and installation conditions is presented in [9]. SCETM models with 1-D representation [10] estimates well the conductor temperature, albeit improved versions, using 2-D representations, have been recently proposed [11]. In relation to the second topic, a probabilistic approach for the estimation of cable temperature exceedance in different time horizons, when increasing the installed power in a OWF in real time (similar concept to overplanting [12]), obtaining acceptable risks when compared to test sets is described in [13]; this allows maximizing the produced instantaneous power, but it does not focus on cable sizing. Finally, a method for deriving equivalent load cyclic load curves from wind speed time series is proposed in [14][15], and along with the standard [6], the recalculation of the cable rating can be done using the traditional rating calculated by means of [5], and adjustment factor $M$. Nevertheless, due to the statistical analysis used to get the mentioned cycle, the full stochastic nature of the wind is approximated and other strategies such as power curtailment must be considered. A systematic method based on dynamic load from offshore wind farms, to construct a "worst-case dynamic load profile" before using a SCETM model for calculating the varying temperature, is proposed in [16], by again, using approximation techniques to obtain such equivalent load profiles.

The deterministic, constant rated power operation implied in the standards is intuitively too conservative considering that OWFs have a typical capacity factor of $0.4-0.5$, and the increase of length of export cables.

The main contribution of this paper is to propose a methodology capable of estimating the lifetime of cables for cumulative fatigue. It combines different concepts, considering realistic operation conditions deemed realistic, such as: time varying cyclic power generation, electro-thermal stress, thermal transients, capacity currents, length-dependent failure probability, and variable external temperature. It also accounts for the ultimate strength limit of the insulation material and, proposing a holistic approach for optimizing the export cable utilization.

This paper is structured as follows: The Section II describes the optimization framework, continuing with the methodology depiction in the Section III, and finally, it is reported the application of the model in a case study with respective sensitivity analysis in the Section IV. The potential crosssection reduction from the point of view of electro-thermal stress and lifetime estimation is pointed out. Conclusions extracted after this work close the article in the Section VI. 


\section{OPTIMIZATION FRAMEWORK}

\section{A. Cost Model}

The cost function to estimate the capital expenses related to the export cables is extracted from [17], where a comprehensive cost survey is provided, and a function is obtained by means of data fitting techniques (1). The cost function is scaled to take into consideration macroeconomics phenomena such as inflation and exchange rate.

$$
C_{t}=A_{p_{t}}+B_{p_{t}} \mathrm{e}^{\left(\frac{C_{p_{t}} S_{n_{t}}}{10^{8}}\right)^{2}}
$$

Where $A_{p_{t}}, B_{p_{t}}$, and $C_{p_{t}}$ are coefficients dependant on the nominal voltage of cable type $t \in \boldsymbol{T}_{\boldsymbol{c}}$ (see Table IV in Appendix), being $\boldsymbol{T}_{\boldsymbol{c}}$ the set of available cables, $S_{n_{t}}$ is the rated power of $t$ in VA (also depending of the rated line to line voltage level, $V_{n}$ ), and $C_{t}$ the cost of $t$ in $€ / \mathrm{km}$. Trenching costs are neglected because the installation route is fixed regardless the cable cross-section, and its value is correlated with the capital cost. Power losses cost are included in the objective function.

\section{B. Optimization Model}

While the formulation of the objective function and the constraints are general, they are adapted to a specific OWF via the input datasets, such as: an associated offshore wind power production potential $\boldsymbol{P}_{i}$, a seabed temperature profile $\boldsymbol{T}_{i}$ (both expressed as $i$-annual time series data in pu and ${ }^{\circ} \mathrm{C}$, respectively), specific soil thermal properties, electric operating conditions, and cable installation conditions.

1) Objective Function: The objective function is defined as an index evaluating the share on the Levelized Cost of Energy (LCOE) of the export cable infrastructure $\left(L C O E_{e s}\right)$, with the mathematical formulation given in (2). Let $x_{i t}$ represent a binary variable, equal to 1 if a cable type $t$ is selected or 0 if not. Additionally, $d$ is the cable total length (in $\mathrm{km}$ ), $r$ is the discount rate (assumed as 5\%), $N_{y}$ is the project lifetime (assumed as 30 years), and $E_{i_{n e t_{t}}}$ is the produced annual energy accounting for power losses (in MWh) [18].

$$
\min \sum_{t \in \boldsymbol{T}_{\boldsymbol{c}}} \frac{d \cdot C_{t} \cdot x_{i t} \cdot r \cdot(1+r)^{N_{y}}}{\left((1+r)^{N_{y}}-1\right) \cdot E_{i_{n^{2} t_{t}}}}
$$

2) Constraints: Let $P_{\text {owf }}, P_{\text {lim }}, \theta_{\text {peak }}, L T_{\text {des }}, F_{p_{\text {des }}}, d_{d e s}$ be parameters representing the OWF installed power (MW), the cable surge impedance power limit for cable $t$ (MW), the allowed maximum instantaneous conductor temperature $\left({ }^{\circ} \mathrm{C}\right)$, cable design lifetime (years), cable design failure probability $(\%)$, and cable testing length $(\mathrm{km})$, respectively. Moreover, let $P_{i_{\text {inct }}}, \theta_{i_{\text {peakt }}}, L T_{i_{P_{\text {inc }}}}$ be non-negative continuous variables modelling the power increase respect to $P_{I E C_{t}}$ calculated with [5] for cable $t(\mathrm{pu})$, the calculated maximum instantaneous conductor temperature for cable $t\left({ }^{\circ} \mathrm{C}\right)$, and the calculated cable lifetime for a given time window $i$ for cable $t$ (years).

$$
\begin{aligned}
& \sum_{t \in \boldsymbol{T}_{\boldsymbol{c}}} x_{i t}=1 \\
& x_{i t} \cdot L T_{i_{P_{i n c_{t}}}} \geq x_{i t} \cdot L T_{\text {des }} \quad \text { At hot spot } \forall t \in \boldsymbol{T}_{\boldsymbol{C}} \\
& x_{i t} \cdot \theta_{i_{\text {peak }}} \leq x_{i t} \cdot \theta_{\text {peak }} \quad \text { At hot spot } \forall t \in \boldsymbol{T}_{\boldsymbol{C}}
\end{aligned}
$$

$$
\begin{gathered}
x_{i t} \cdot P_{i_{i n c_{t}}} P_{I E C_{t}} \leq x_{i t} \cdot P_{\text {lim }_{t}} \quad \forall t \in \boldsymbol{T}_{\boldsymbol{c}} \\
x_{i t} \cdot P_{i_{i n c_{t}}} P_{I E C_{t}} \geq x_{i t} \cdot P_{o w f} \quad \forall t \in \boldsymbol{T}_{\boldsymbol{c}} \\
P_{\text {lim }_{t}}=\frac{\left|V_{S}\right|\left|V_{R}\right|}{\left|B_{t}\right|}-\frac{\left|A_{t}\right|\left|V_{R}^{2}\right|}{\left|B_{t}\right|} \cos \left(\beta_{t}-\alpha_{t}\right) \quad \forall t \in \boldsymbol{T}_{\boldsymbol{c}}
\end{gathered}
$$

Constraint (3) ensures that the solution has only one cable type. Constraint (4) guarantees that the calculated cable lifetime operating under a given time window and real conditions, is not lower than the one given as design value. Constraint (5) limits the calculated maximum instantaneous conductor temperature, so the material ultimate strength is not met. Constraint (6) permits abiding the cable stability limit. Constraint (7) matches the increase power with the OWF installed power. Constraint (8) calculates the stability or cable surge impedance power limit, where $V_{S}$ and $V_{R}$ are line-toline voltages (assumed to be the rated value), and $\left|A_{t}\right| \angle \alpha_{t}$ and $\left|B_{t}\right| \angle \beta_{t}$ represents the cable two-ports model for a cable $t$ [19].

The model presented from (2) to (8) is non-linear. However, the search space is rather small, since only a limited numbers of cable types are available from manufacturers. This allows use of simplistic human-driven or brute-force optimization methods to select proper export cable satisfying (2) to (8). The main challenge, however, is the estimation of lifetime which has not yet been addressed in the field of OWF design. The proposed approach for lifetime calculation is described in the next section.

\section{Methodology}

The steps of the proposed methodology are presented in the Fig. 1. The main objective of this method is to provide a framework that allows calculating offline the dynamic loadability of export cables for OWF.

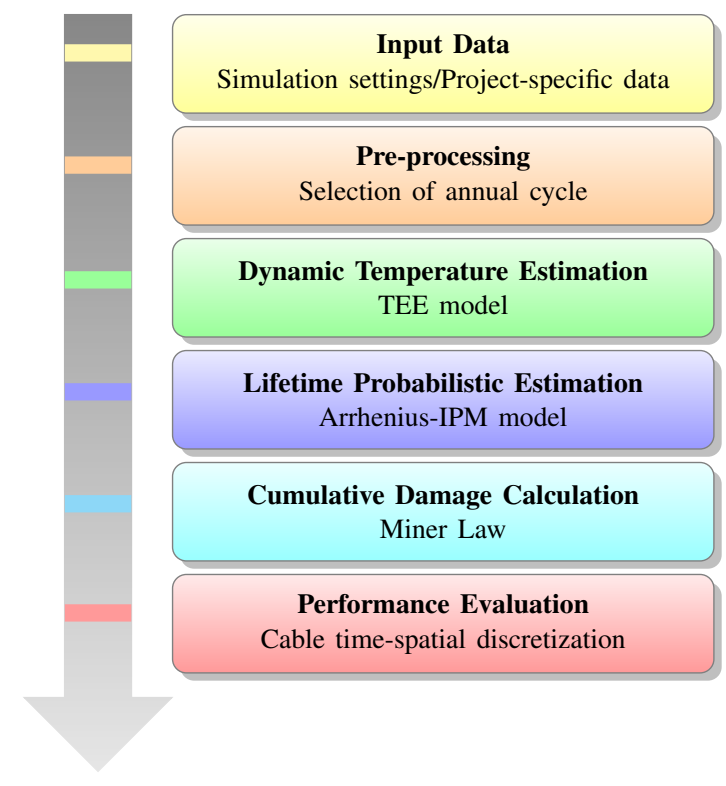

Fig. 1: Lifetime estimation method for OWF's high voltage AC export cables. 


\section{A. Input Data}

The quality and volume of project-specific datasets has pronounced relevance, influencing a lot the results.

1) Simulation Setting: Defines the main simulation parameters: i) seabed multilayer definition $N$ (as introduced in [20]), ii) cables lifetime design information: $L T_{d e s}, d_{d e s}$, and $F_{p_{\text {des }}}$, iii) cables catalogue, and iv) geometrical and thermal information of the cables inner layers.

2) Project-specific data: Gathers OWF electrical information $\left(P_{o w f}\right),\left(V_{n}\right)$, plus: i) system nominal frequency $f_{n}$, ii) wind farm aggregated power factor $p f$, and iii) series-shunt compensation (indicated as a percentage of the cable total inductance-capacitance). It also defines cable laying conditions: iv) total length $d$, v) buried depth $b_{d}$, and vi) cables spacing $s$. Finally, it includes: vii) annual power production time series $\boldsymbol{P}_{i}$, and viii) annual seabed temperature time series $\boldsymbol{T}_{i}$, along with thermal information of the seabed: ix) thermal resistivity $\rho_{t h}$, and $\mathrm{x}$ ) specific heat $c_{t h}$. Information related to the seabed is assumed to be spatial-uniform along the cable route.

\section{B. Pre-processing}

The cycle time basis selected is a natural year because it is the typical time horizon used for calculating Discounted Cash Flow, and the economic metrics quantifying the project performance for funding plans, such as Net Present Value, LCOE, and Internal Rate of Return. On the other hand, selecting this time frame, represents a conservative approach itself that allows considering the most unfavorable scenario from the point of view of cable stress.

Let $\boldsymbol{P}$ represents the set of available annual time series, so $\boldsymbol{P}=\left\{\boldsymbol{P}_{1}, \cdots, \boldsymbol{P}_{y}\right\}$, equivalently for the seabed temperature, $\boldsymbol{T}=\left\{\boldsymbol{T}_{1}, \cdots, \boldsymbol{T}_{y}\right\}$, where $y \in \mathbb{N}^{+}$represents the size of the sets. The analysis presented in the Fig. 1 is sequentially and independently repeated for each triple $\left(\boldsymbol{P}_{i}, \boldsymbol{T}_{i}, t\right)$, where $\boldsymbol{P}_{i} \in \boldsymbol{P}, \boldsymbol{T}_{i} \in \boldsymbol{T}$, and $t \in \boldsymbol{T}_{\boldsymbol{c}}$, obtaining in each case a cable lifetime estimation $L T_{i_{P_{\text {inct }}}}$, and peak temperature $\theta_{i_{\text {peak }}}$. The optimization procedures consists on finding the cable leading to the minimum objective function, satisfying (3) to (8), for all $i \in\{1, \cdots, y\}$.

\section{Dynamic Temperature Estimation}

A Thermo-Electrical Equivalent (TEE) model based on the works [21] and [22] have been developed and calibrated as presented in [20]. The theoretical and practical validation of this model can be found in [16] and [10].

For a triple $\left(\boldsymbol{P}_{i}, \boldsymbol{T}_{i}, t\right)$, where $\boldsymbol{\Theta}_{i_{t}}$ is the calculated instantaneous conductor temperature in year $i$ for cable $t$ at hot spot (i.e., considering capacitive currents), such as $\boldsymbol{\Theta}_{i_{t}}=$ $\left\{\theta_{i_{1_{t}}}, \cdots, \theta_{i_{j_{t}}}, \cdots, \theta_{i_{h_{t}}}\right\}$, where $h$ is the number of elements of $\boldsymbol{P}_{i}$ and $\boldsymbol{T}_{i}$. As stated in Section II-B, $\max \boldsymbol{\Theta}_{i_{t}}=\theta_{i_{\text {peakt }}}$.

\section{Probabilistic Lifetime Estimation}

Many different models can be used for inferring the lifetime of power system components. A review of such models obtained by means of accelerated test experiments is presented in [23]. A benchmarking between different electro-thermal stress models for power cables has been done, such as Zurkov, Crine and Arrhenius-IPM models, each within the probabilistic framework needed for associating time-to-failure to reliability. All these models present different analytical expressions and parameter values, however in general they all provide same indications regarding lifetime, being the Arrhenius-IPM model the most conservative for a wide operation range [24]. The parameters of the Arrhenius-IPM model, based on accelerated test experiments, are available in the literature [25].

According to [24], let (9) represent the mathematical expression for combining two single-stress life models and their synergism: the so-called thermal stress model, Arrhenius and for the electric stress, the Inverse Power Model (IPM). Where $\left(\frac{1}{\theta_{0}}-\frac{1}{\theta_{i_{j t}}}\right)$ defines the so-called conventional thermal stress $\left(\theta_{i_{j_{t}}}\right.$ is the conductor temperature in Kelvin for a year $i$, cable type $t$, and time slot $1 \leq j \leq h$, and $\theta_{0}$ the room reference temperature), parameter $B=\frac{\Delta W}{k}(\Delta W$ is the activation energy of the main thermal degradation reaction, and $k$ is the Boltzmann constant), $n_{0}$ is the so-called voltage endurance coefficient (VEC) at $\theta_{0}, b$ is the parameter linking the synergism between electric and thermal stress, $E$ is the electric field of the cable under analysis, $E_{0}$ is the value of electric field below which electric aging is considered neglected, and $\alpha_{0}$ is the cable's life at $\theta_{0}$ and $E_{0}$.

$\alpha_{t}\left(E, \theta_{i_{j_{t}}}\right)=\alpha_{0} \cdot \mathrm{e}^{-B \cdot\left(\frac{1}{\theta_{0}}-\frac{1}{\theta_{i_{j_{t}}}}\right)} \cdot\left(\frac{E}{E_{0}}\right)^{-\left(n_{0}-b \cdot\left(\frac{1}{\theta_{0}}-\frac{1}{\theta_{i_{j_{t}}}}\right)\right)}$

According to [26] the most accepted cumulative probability density function (pdf) to relate time-to-failure and failure probability for $\mathrm{HV}$ equipments is the Weibull pdf, as it is expressed in (10), where $t_{P_{f}}$ is the life at failure probability $P_{f}, \alpha_{t}\left(E, \theta_{i_{j_{t}}}\right)$ is the scale factor of the pdf which is function of $E$ and $\theta_{i_{j_{t}}}$ (time-to-failure for a probability of 0.632 ), and $\beta_{t}$ is the shape parameter of the pdf.

$$
\begin{gathered}
P_{f}\left(t_{P_{f}} ; E, \theta_{i_{j_{t}}}\right)=1-\mathrm{e}^{-\left(\frac{{ }^{t} P_{f}}{\alpha_{t}\left(E, \theta_{i_{t}}\right)}\right)^{\beta_{t}}} \\
t_{P_{f}}=\left[-\ln \left(1-P_{f}\right)\right]^{\frac{1}{\beta_{t}}} \cdot \alpha_{t}\left(E, \theta_{i_{j_{t}}}\right) \\
L_{P_{f}}\left(E, \theta_{i_{j_{t}}}, P_{f}\right)=\left[-\ln \left(1-P_{f}\right)\right]^{\frac{1}{\beta_{t}}} \cdot \alpha_{0} \cdot \mathrm{e}^{-B \cdot\left(\frac{1}{\theta_{0}}-\frac{1}{\theta_{i_{t}}}\right)} \\
\cdot\left(\frac{E}{E_{0}}\right)^{-\left(n_{0}-b \cdot\left(\frac{1}{\theta_{0}}-\frac{1}{\theta_{i_{t}}}\right)\right)}
\end{gathered}
$$

Re-arranging (10) with respect to $t_{P_{f}}$, it is obtained (11). If one uses the electro-thermal stress model Arrhenius-IPM given in (9), which is valid for failure probability of 0.632 , then (12) is found.

Equation (12) models the probabilistic time-to-failure of a cable for a set of operative conditions, $E, \theta_{i_{j_{t}}}$, and $P_{f}$. It is valid for cables specimen used in laboratory tests considering that the pdf and stress model is representative for the whole range of operation [25]. To extrapolate this result to real-size cables for projects applications, the probabilistic enlargement 
law is applied [27], see (13). Longer lengths means more potential failure spots, less lifetime.

$$
L_{D}\left(E, \theta_{i_{j_{t}}}, P_{D}\right)=L_{P_{f}}\left(E, \theta_{i_{j_{t}}}, P_{f}\right) \cdot\left[\frac{\ln \left(1-P_{D}\right)}{D \cdot \ln \left(1-P_{f}\right)}\right]^{\frac{1}{\beta_{t}}}
$$

Where $D$ is the enlargement factor that depends on the ratios of cables length $\left(l_{D}\right.$ and $\left.l_{f}\right)$ and conductors radius $\left(r_{D}\right.$ and $\left.r_{f}\right)$ of real-size and cable specimen, respectively, as represented in (14).

$$
D=\frac{l_{D}}{l_{f}} \cdot\left(\frac{r_{D}}{r_{f}}\right)^{2}
$$

Finally, inserting (12) in (13), the probabilistic lifetime estimation model for real-size cables is obtained:

$$
\begin{aligned}
L_{D}\left(E, \theta_{i_{j_{t}}}, P_{D}\right)= & {\left[\frac{-\ln \left(1-P_{D}\right)}{D}\right]^{\frac{1}{\beta_{t}}} \cdot \alpha_{0} \cdot \mathrm{e}^{-B \cdot\left(\frac{1}{\theta_{0}}-\frac{1}{\theta_{i_{j_{t}}}}\right)} } \\
& \cdot\left(\frac{E}{E_{0}}\right)^{-\left(n_{0}-b \cdot\left(\frac{1}{\theta_{0}}-\frac{1}{\theta_{i_{t}}}\right)\right)}
\end{aligned}
$$

The parameters for the model of (15) extracted from [24] are presented in Table I. The probabilistic lifetime model is calibrated to hold for XLPE insulation cables considered in this study. Accelerated life tests done in [25] on cables specimen of $0.4 \mathrm{~m}$ long, with solid copper conductor radius of $0.9 \mathrm{~mm}$, inner semicon thickness of $0.5 \mathrm{~mm}$, and insulation thickness of $1.5 \mathrm{~mm}$ were used to derive the parameters.

\section{TABLE I}

PARAMETER VALUES FOR LIFETIME ARRHENIUS-IPM MODEL

\begin{tabular}{cccccccc}
\hline$b\left[\mathrm{~K} \frac{\mathrm{mm}}{\mathrm{kV}}\right]$ & $B[\mathrm{~K}]$ & $n_{0}$ & $V_{n}[\mathrm{kV}]$ & $E_{0}\left[\frac{\mathrm{kV}}{\mathrm{mm}}\right]$ & $E_{n}\left[\frac{\mathrm{kV}}{\mathrm{mm}}\right]$ & $\theta_{0}[\mathrm{~K}]$ & $\beta_{t}$ \\
\hline 4420 & 12430 & 15 & 145 & 5 & 7.2 & 296.5 & 2 \\
\hline
\end{tabular}

The parameter $\alpha_{0}$ has to be calculated to scale the pdf accordingly to the input information, i.e., cable with specific $d_{d e s}, L T_{d e s}$, and $F_{p_{d e s}}$, operating at rated temperature $\theta_{i_{j_{t}}}=\theta_{n}$, for all $j \in\{1, \cdots, h\} \wedge i \in\{1, \cdots, y\}$, and continuous nominal electric field, $E_{n}$. Additionally it is assumed to be invariant over the operation range considered in this work. Parameters $E_{0}$ and $E_{n}$, have to be extrapolated in function of the nominal voltage of the particular cable under analysis. It is assumed these parameters are constant throughout the whole range of stress levels.

\section{E. Cumulative Damage}

Let $\delta t$ be an infinitesimal increment of time within a time slot $j$ in $\boldsymbol{P}_{i}$, so the infinitesimal loss-of-life fraction of the cable $t$, is calculated as:

$$
\delta L F_{j}=\left.\frac{\delta t}{L_{D}\left(E, \theta_{i_{j_{t}}}, P_{D}\right)}\right|_{E=E_{n}, \theta_{i_{j_{t}}}, P_{D}=F_{p_{d e s}}}
$$

Integrating the previous expression along $j$ (thermal time constant of cables is slow so it is a reasonable assumption), the loss-of-life fraction in this time slot is obtained in (16):

$$
L F_{j}=\left.\frac{1}{L_{D}\left(E, \theta_{i_{j_{t}}}, P_{D}\right)}\right|_{E=E_{n}, \theta_{i_{j_{t}}}, P_{D}=F_{p_{d e s}}}
$$

According to the Miner's cumulative damage theory [28], summing up the loss-of-life fraction for every time slot, defines the estimated lifetime of the component under analysis when the result is equal to one. Therefore, (17) allows calculating the number of cycles $\left(L T_{i_{P_{\text {inc }}}}\right.$ years) of the cable to failure, accounting for the effects of cumulative damage, for the annual time series $i$ and cable type $t$.

$$
L T_{i_{P_{\text {inct }}}}=\frac{1}{\sum_{j=1}^{h} L F_{j}}
$$

\section{F. Performance Evaluation}

The total loss calculation process allows an holistic estimation, taking the variability of current along the cable into consideration [29]. Dynamic temperature estimation includes the effects of conductor resistance variation in function of its temperature. Temperature varies in time resulting in variation of the conductor and other associated losses (screen, armouring, and dielectric). Consequently, the total losses $\left(T L_{i_{t}}\right)$ calculation for a cable $t$ is defined in (18) [20].

$T L_{i_{t}} \approx 3 \cdot\left(1+\lambda_{1}+\lambda_{2}\right) \cdot \sum_{l=1}^{l_{D_{T}}} \sum_{j=1}^{h} R_{c_{t}}(l, j) \cdot I_{t}(l, j)^{2}+3 \cdot W_{d_{t}}$

where $l_{D_{T}}, h, R_{c_{t}}(l, j), I_{t}(l, j)$, and $W_{d_{t}}$ are the total number of sections that the cable is divided into, total number of hours in the year under analysis, $i$, as stated in Section III-C, conductor resistance in ohms, current in amperes (being these two last function of distance and time), and total dielectric losses, respectively. The factor $\left(1+\lambda_{1}+\lambda_{2}\right)$ accounts for the screen and armouring losses, while the constant 3 is for the three-phase system. It is observed that $l_{D_{T}}$ should be between $10-20$ (depending on cable total length) to achieve a proper computation time-quality balance [20].

\section{Case Study}

As a case study the OWF Arcadis Ost 1 (GW1) (see Fig. 2 ), foreseen to be constructed in the Baltic Sea in 2030, is considered.

Pre-feasibility studies project a total installed capacity of $456 \mathrm{MW}$ (38 Wind Turbines of $12 \mathrm{MW}$ ), routing length of the export cables of $d=89 \mathrm{~km}$, nominal voltage $V_{n}=275 \mathrm{kV}$, nominal frequency $f_{n}=50 \mathrm{~Hz}, p f=1$, without compensation units.

The aim of the analysis is to illustrate how, using the proposed methodology, the sizing of the export cable can be done taking into account the lifetime of the cable. Input data related to cables is extracted from [30]; other inputs are presented in the Table II. Availability of seabed temperature time series is scarce, hence a synthetic time series based on info from 


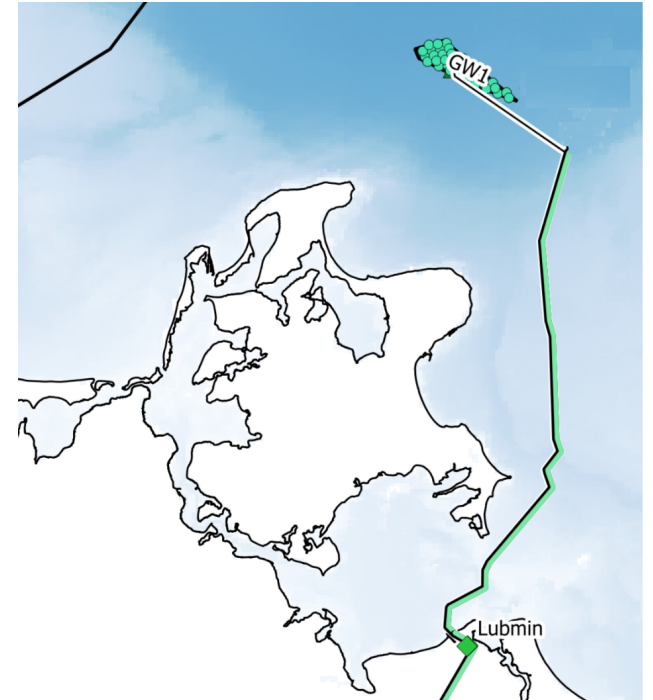

Fig. 2: Map of the project area of the case study.

the Bornholm Basic area [31] was created. The time series vary between $1{ }^{\circ} \mathrm{C}-10{ }^{\circ} \mathrm{C}$ and takes into account the seasonal fluctuations.

TABLE II

CASE STUDY SIMULATION INPUTS

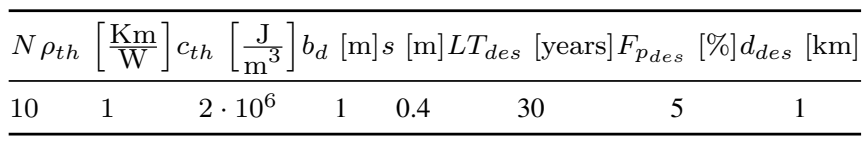

\section{Simulation Results and Sensitivity Analysis}

This Section is divided in two parts; Section V-A for the analysis considering the parameters of the Table II and the described time series, benchmarking the proposed method against [5] and [7], and Section V-B for presenting a sensitivity analysis that aims at quantitatively assessing the impact of the uncertainty in the soil thermal resistivity and seabed temperature time series. For both analyses, 35 years of simulated offshore wind power production time series are used simulated with CORWIND [32]- [33].

\section{A. Cable Sizing Results}

The proposed methodology is benchmarked against two approaches: first, the one recommended in [5], and second, by using the worst case dynamic load profiles, as studied in [7], which actually has been used lately by OWF developers in the tendering process with cable manufacturers.

The method in [5] is straight-forward, consisting only in a multi-parameter static equation for getting the continuous current $I_{t}$, to be transmitted during infinite time, in order to obtain a continuous conductor temperature equal to $90^{\circ} \mathrm{C}$. The smaller cable $t$ with $I_{t}$ equal or greater than the total current (including capacitive currents) at hot spot is selected. The resultant sizing following this approach is a $1,200 \mathrm{~mm}^{2}$ cable.

Recently, a more sophisticated method is being adapted as industrial practice, as detailed in [7] (CIGRÉ: Working Group
B1.40) and [16]; this is represented by a four-step signal, calculated using the highest RMS values computed through different periods, sweeping through the yearly data set by means of a rolling RMS filter starting at each singular data point. A pre-processing analysis is needed to be carried out to find the set of periods of interest. In the study presented in [16], it has been concluded that the periods of 7 days, 10 days, 40 days, and 365 days capture reasonably the most representative windy days in a windy year; this fact has been validated using the data set available in this paper. Thus, in a temporal sequential ordering, the pre-conditioning current is derived calculating the RMS value for the whole data set, lasting 308 days (remanining days after the periods 7,10 , and 40), then the greatest yearly RMS value using a period length of 7 days is obtained, keeping the same procedure for the periods of 10 days and 40 days, while not overlapping the periods between them. Note that this sequential arrangement represents a conservative criterion itself, because of the assumed steadily increase of current with time.

After applying the aforementioned process to this case study, the profile of worst case load pattern is displayed in the Fig. 3. This step-wise pattern is normalized respect to the total current at hot spot, and the main aim is to be provided to cables manufacturers, in order to have a common framework to compare their bids. The smaller cable $t$ with $\theta_{\text {peak }}$ (note the elimination of the subscript $i$ because there is a single pattern representing all the years) inferior than $90^{\circ} \mathrm{C}$ is selected.

Using the pattern of the Fig. 3, and considering the synthetic seabed temperature time series, a $630 \mathrm{~mm}^{2}$ cable is chosen, exhibiting a $\theta_{\text {peak }_{t}}=88.71^{\circ} \mathrm{C}$.

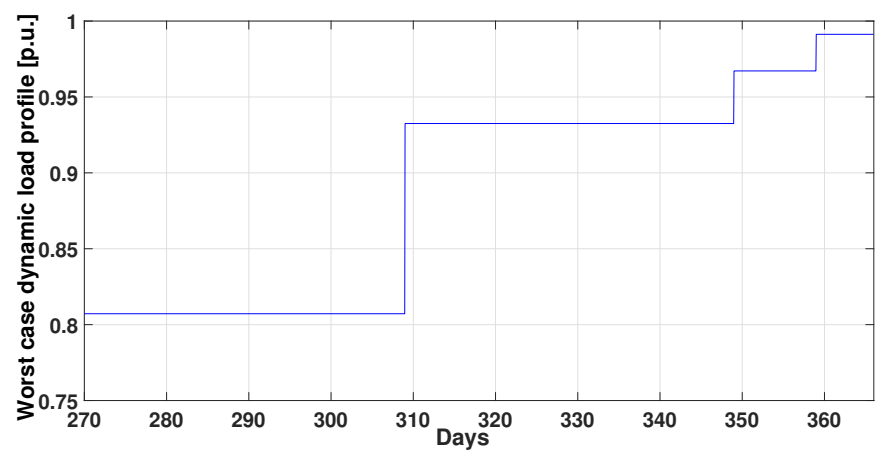

Fig. 3: Profile of worst case dynamic load pattern [7].

Employing the full temporal data set according the proposed methodology, the peak temperature $\left(\theta_{i_{\text {peakt }}}\right)$ obtained for all points defined by $\left(\boldsymbol{P}_{i}, \boldsymbol{T}_{i}, t\right)$ is given in Fig. 4 . The results indicate that all cables - except the $500 \mathrm{~mm}^{2}$ cable - satisfy constraint (5), namely do not exceed the rated temperature limit (indicated by a red dotted line, $\theta_{\text {peak }}=\theta_{n}$ ). The results also show that the $1,200 \mathrm{~mm}^{2}$ cable -the size that results when using standard [5]- is significantly underused as expected, exhibiting a maximum $\theta_{i_{\text {pea }} k_{t}}$ of $62{ }^{\circ} \mathrm{C}$. On the other hand, the $630 \mathrm{~mm}^{2}$ cable -sized according the worst case pattern- presents a maximum $\theta_{i_{\text {peak }}}$ of $88.69^{\circ} \mathrm{C}$, showing that the equivalent step profile is on the conservative side $\left(\theta_{\text {peak }_{t}}=88.71^{\circ} \mathrm{C}\right)$, and achieves to capture a realistic harsh windy scenario; these results confirm the validity of the 
equivalent cycle for the purpose of facilitating the tendering process, nevertheless representing an approximation of the real time series, which provide more insight about the power production of the OWF, and in fact, conceptually necessary to perform lifetime studies for cumulative damage. Furthermore, the variability of $\theta_{i_{\text {peak }}}$ for each cable $t$, in function of the year $i$, depends strongly on the cable's physical properties.

As shown in Fig. 4, the spread of $\theta_{i_{\text {peak }}}$ decreases with the size of the cables; In fact, from other dispersion perspective, for the $630 \mathrm{~mm}^{2}$ cable, the mean value is $85.47^{\circ} \mathrm{C}$ with a standard deviation of $1.27^{\circ} \mathrm{C}$, while for the type $800 \mathrm{~mm}^{2}$, these numbers change to $73{ }^{\circ} \mathrm{C}$ and $0.96{ }^{\circ} \mathrm{C}$, respectively. This points out that the conductor cable size has a direct relation with the temperature variability due to the power production fluctuations, smaller sizes leading to increased ramping. Based on the thermal results, the cable size could be either $630 \mathrm{~mm}^{2}$ or $800 \mathrm{~mm}^{2}$. The conductor temperature time series for the cables $630 \mathrm{~mm}^{2}$ (red line) and $800 \mathrm{~mm}^{2}$ (blue line), at the year with highest $\theta_{i_{\text {peak }}}$, are given in Fig. 5 .

As it is appreciable, the instantaneous conductor temperatures between both cables types are considerable different and more critical for smaller cable. For instance, a change in power results in a larger temperature ramping for the smaller cable, which has a lower temperature time constant (see the zoomedin graph in the Fig. 5 for the first day of operation); the latest is consequence of the growth rate difference among both cable types, and has as a consequence a different conductor temperature frequency distribution as shown in the Fig. 6. It is evident that the conductor temperature distribution resembles a bimodal distribution, showing higher peaks and higher frequency for the $630 \mathrm{~mm}^{2}$. The proposed method results in indicating the same cable as the one in [7]. However, the deterministic nature of the latter methods does not allow assessing the reliability of the cable in function of its length. Hence, it is beneficial to move towards a probabilistic approach to avoid too optimistic procedures which may potentially lead to operational failures. The different profile of instantaneous

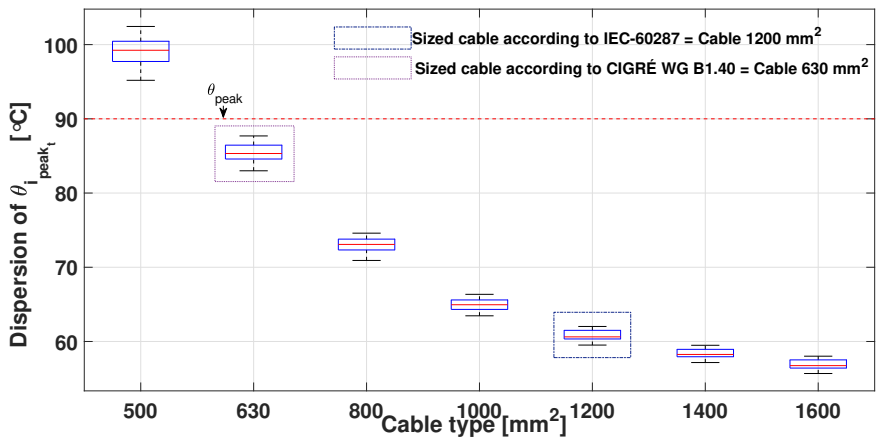

Fig. 4: Overall thermal simulation results.

temperature yields to different lifetime estimations, due to the different fatigue levels induced by their electro-thermal stresses, as captured in the Fig. 7, and with effect on economic metric as displayed in Fig. 8. Lifetime estimation is given as a ratio of calculated to design values, as expressed in $\left(L T_{i_{\text {ratiot }}}=\frac{L T_{\text {des }}}{L T_{i_{\text {Pinct }}}}\right) \leq 1$, in order to minimize uncertainties on the probabilistic lifetime estimation model.

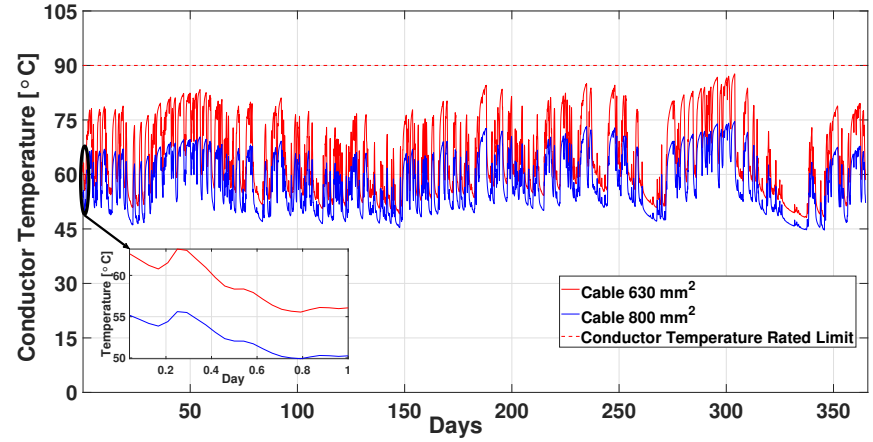

Fig. 5: Cables conductor temperature time series.

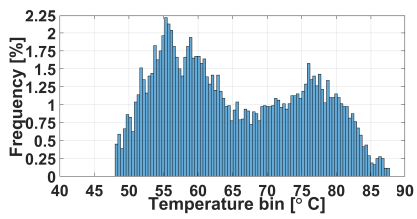

(a) Cable $630 \mathrm{~mm}^{2}$

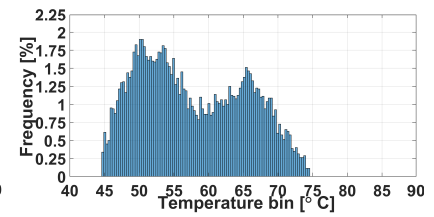

(b) Cable $800 \mathrm{~mm}^{2}$
Fig. 6: Cables conductor temperature histogram.

As expected, the $630 \mathrm{~mm}^{2}$ cable exposed to more critical conductor temperature, exhibits a lifetime ratio outside the bounds of the optimization model. In contrast, the $800 \mathrm{~mm}^{2}$ cable satisfies this constraint for all the simulated annual cycles while satisfying all other constraints, resulting to a value of $P_{i_{\text {inc }}}=0.99$, which also agrees with the evidence of an underestimating criterion proposed by IEC standard [5] $\left(P_{i_{\text {inc } c_{t}}}=0.84\right.$ for $\left.1,200 \mathrm{~mm}^{2}\right)$. The mean and standard deviation values of $L T_{i_{\text {ratiot }}}$ for selected $800 \mathrm{~mm}^{2}$ cable are 0.58 and 0.06 , respectively. For $\theta_{i_{\text {peakt }}}$ these values are $73{ }^{\circ} \mathrm{C}$ and $0.96^{\circ} \mathrm{C}$, correspondingly, as mentioned before. The standard deviations of these two variables are considered acceptable to show robustness towards different annual generation profiles. Although the proposed framework suggests a cable one size up compared to [7], the decision is based on a more informed and robust evaluation of the operating conditions of the cable, thus, decreasing the likehood of failures.

The variability difference for different cables on $L T_{i_{\text {ratiot }}}$ and $\theta_{i_{\text {peakt }}}$, can be explained based on the fact that larger cables have larger time constants (slower dynamic response), hence the reaction speed due to power changes is less pronounced than in smaller cables. This is particularly important condition, since the power production is a stochastic variable hard to forecast. If the conductor temperature uncertainty can be decreased by the physical properties of the cables itself, it can help to a more reliable operation based on analysis using power production either simulated or measured from a set of years. Nonetheless, going from a $1,200 \mathrm{~mm}^{2}$ (criterion of [5]) to a $800 \mathrm{~mm}^{2}$ cable has as direct consequence on decrease of initial investment, but also with detriment of larger total power losses. Consequently, the performance evaluation step introduced in Section III-F, is applied in order to estimate the total electric losses and to calculate the $L C O E_{e s}$. Equation (2) is systematically applied for different cables and different 


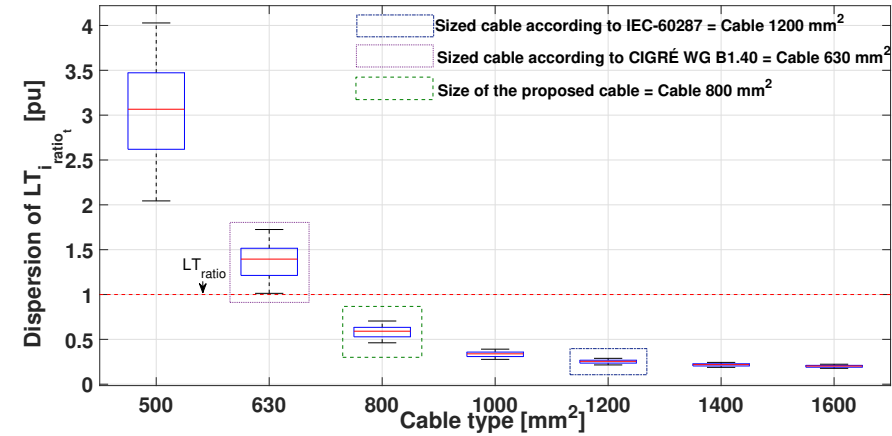

Fig. 7: Overall lifetime simulation results.

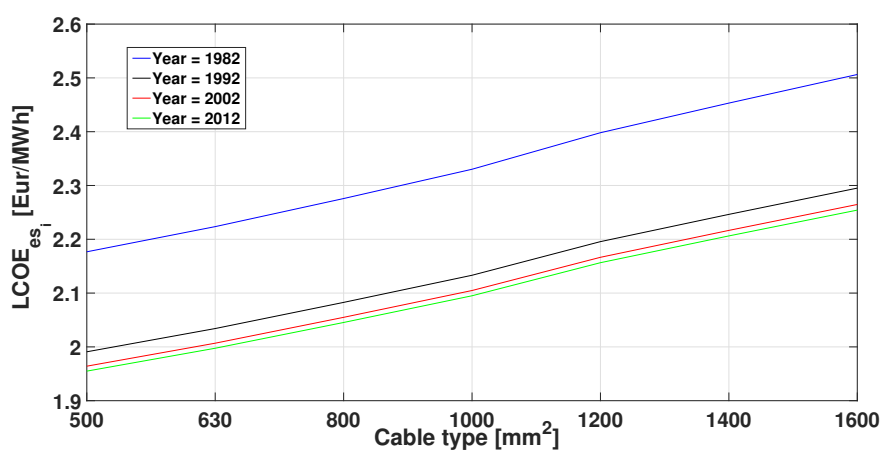

Fig. 8: $L C O E_{e s}$ in function of cable type for different years.

years obtaining the plot represented in the Fig. 8. It is evident that regardless the year under analysis, the $L C O E_{e s}$ function is increasing monotonically in function of larger cables as presented in Fig. 8; likewise, the curves for different years present no intersections between them, which in combination of the previous point, allows concluding that the objective function is unequivocally minimized for the smallest feasible cable taking into consideration the full data set of annual generation.

Overall, the reduction in the cross-section of the export cable provides a reduction of $5 \%$-assuming the most expensive yearin the $L C O E_{e s}$ when considering solely the related costs to this component.

\section{B. Sensitivity Analysis}

To assess the impact of the input data uncertainty on the results, a sensitivity analysis is done. Soil thermal resistivity $\left(\rho_{t h}\right)$ and seabed temperature $(\boldsymbol{T})$ are selected as they are the data with the lower availability.

This analysis consists in combining discrete changes (respect to the base case values) on $\rho_{t h}$ and $\boldsymbol{T}$, expressed as $\Delta \rho_{t h}=$ $\{0,0.2\} \frac{\mathrm{Km}}{\mathrm{W}}$ and $\Delta T=\{0,5\}{ }^{\circ} \mathrm{C}$, respectively. The results are presented in the Table III, where it is clear that an individual increase of $20 \%$ on $\rho_{t h}\left(0.2 \frac{\mathrm{Km}}{\mathrm{W}}\right)$, and $50 \%$ of the peak value on $\boldsymbol{T}\left(5^{\circ} \mathrm{C}\right)$, causes that for each case, a larger cable would be required, namely $1,000 \mathrm{~mm}^{2}$; furthermore, for the critical condition of a simultaneous deviation of these design values, the impact would be large, resulting in selecting a $1,200 \mathrm{~mm}^{2}$. The effect of the individual and combined change of $\rho_{t h}$ and $\boldsymbol{T}$ (using reasonable deviations) is not negligible as the results reveal, since the cable size according to the framework proposed in this paper, should be scaled up one or two steps when compared to the base case conditions. It is recommended therefore to dedicate efforts towards gathering high quality data related to these parameters and their typical fluctuations along the year; as a result, operational failure risks can be minimized while optimally sizing the export cable. A high resolution uncertainty analysis would also help determining with higher accuracy the weight of the parameters leading to better performance of the proposed methodology. The last column in Table III show the final variation of the

TABLE III

RESUlTS OF SENSITIVITY ANALYSIS

\begin{tabular}{cccc}
\hline$\Delta \rho_{t h}\left[\frac{\mathrm{Km}}{\mathrm{W}}\right]$ & $\Delta \boldsymbol{T}\left[{ }^{\circ} \mathrm{C}\right]$ & Cable Type $\left[\mathrm{mm}^{2}\right]$ & $\Delta L C O E_{\text {es }}[\%]$ \\
\hline 0 & 0 & 800 & 5 \\
\hline 0 & 5 & 1000 & 3 \\
\hline 0.2 & 0 & 1000 & 6.8 \\
\hline 0.2 & 5 & 1200 & 4 \\
\hline
\end{tabular}

$L C O E_{e s}$ savings (respect to [5] criterion). The latest results show that the lowest savings are achieved with a solo variation on $\boldsymbol{T}$, since the IEC standard recommends keeping a constant external temperature which in this cases is still higher than $\boldsymbol{T}+5^{\circ} \mathrm{C}$, similarly the largest saving is found with a solo variation on $\rho_{t h}$, given the strong dependency of the static equation on this parameter.

Finally, the impact of the export cables length is investigated by means of Fig. 9 and Fig. 10. The following simulation considers the most critical condition for $\rho_{t h}$ and $\boldsymbol{T}$, and a cable total length of $32.5 \mathrm{~km}$. It is evident according to the Fig. 9 that all the cables exhibit a $\theta_{i_{\text {peakt }}}$ never higher than $90^{\circ} \mathrm{C}$, with exception of the cable $500 \mathrm{~mm}^{2}$, which surpasses this value for almost $50 \%$ of the cases. However, when evaluating the level of exceedance in terms of frequency for that year with the highest $\theta_{i_{\text {peakt }}}$, it is found out that for the temperature range between $90^{\circ} \mathrm{C}-95^{\circ} \mathrm{C}$, the accumulated probability of occurrence is lower than $1.75 \%$.

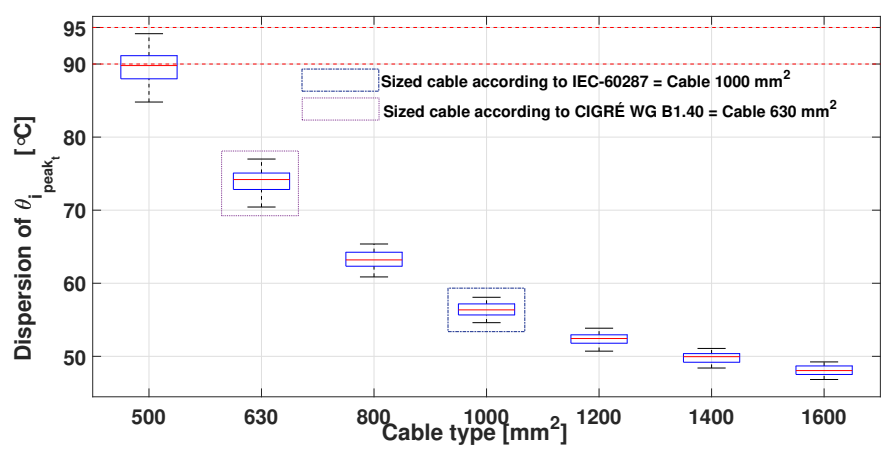

Fig. 9: Sensitivity of overall thermal simulation results. $d=32.5 \mathrm{~km}$. 


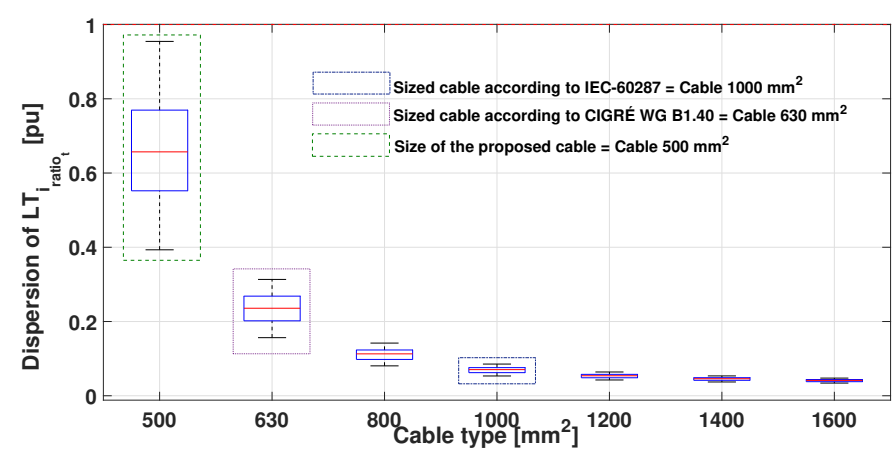

Fig. 10: Sensitivity of overall lifetime simulation results. $d=32.5 \mathrm{~km}$.

This raises the question whether is too conservative to limit the instantaneous conductor temperature to $90{ }^{\circ} \mathrm{C}$, value that is defined as a limit for accumulated stress when operating continuously at this degradation rate in the insulation material [34], but not representing the ultimate strength limit. In fact, in Fig. 10 is shown that the $500 \mathrm{~mm}^{2}$ cable satisfies the lifetime constraint for all the generation scenarios, therefore by means of a constraint relaxation of $\theta_{\text {peak }}$ to $95^{\circ} \mathrm{C}$, this cable type could be choose under these conditions, obtaining a $L C O E_{e s}$ reduction of almost $7 \%$. Note that for this case, the cable total length is less restricting from a lifetime estimation probabilistic point of view, therefore improving the size not only compared to [5], but also to [7], with a reduction of roughly $2 \%$.

\section{CONCLUSION}

The proposed methodology provides a rigorous, and transparent approach for minimizing the $L C O E_{e s}$ related to high voltage AC export cables for OWFs.

The main constraints are the maximum instantaneous conductor temperature (which is related to the ultimate strength of the insulation material), the estimated lifetime of the cable (obtained as an accumulation of stress over the cable operational lifetime), and the electric stability limit.

The methodology is applied systematically and in a cyclic-fashion, for each available annual generation and seabed temperature time series, obtaining as a final output the cable leading to the cheapest $L C O E_{e s}$ while evaluating for the whole data set the abiding of security operational constraints.

Results show the potential of this methodology in terms of $L C O E_{e s}$ reduction. According to the simulations, a reduction up to $5 \%$ can be achieved, while guaranteeing all the operational security constraints.

An uncertainty analysis of the parameters deemed to be the least available: soil thermal resistivity and seabed temperature, showed that the impact on cable sizing can be significant.

The analysis highlights the benefits for proper measurement/estimation of these parameters in the planning stage of a OWF project for reducing the risks of failures. Bigger cables drive to larger $L C O E_{e s}$, however have the advantage of less sensitivity to large generation changes, minimizing the uncertainty introduced by the estimation of the expected power generation levels and variability. The distance from shore also has an impact on the cable sizing; for larger distances the cables lifetime is the limiting factor, while for shorter distances the ultimate thermal strength takes that role. A relaxation of the maximum instantaneous temperature can allow for a further reduction in the cable sizing for shorter distances, providing cost reductions even compared to the most updated industrial practices.

The proposed methodology depends on the accuracy of several parameters: the values of the lifetime electro-thermal and failure extrapolation models, power generation cycles, seabed soil temperature, and thermal properties of the soil and the cable. To partially mitigate this, the lifetime estimation is normalized, rather than in absolute values. Comprehensive uncertainty analysis is recommended to be performed to quantify accurately this phenomenon, based on real data if possible. Furthermore, availability of real cable failure data will help for further validating the methodology. Future work direction will move towards adaptation of the methodology to other cables technologies, and identification of hot spots, real-time monitoring, and effective asset management strategies.

\section{APPENDIX}

TABLE IV

\section{CABLES COST COEFFICIENTS}

\begin{tabular}{cccc}
\hline$V_{n}[\mathrm{kV}]$ & $A_{p_{t}}$ & $B_{p_{t}}$ & $C_{p_{t}}$ \\
\hline 22 & $0.284 \cdot 10^{6}$ & $0.583 \cdot 10^{6}$ & 6.15 \\
\hline 33 & $0.411 \cdot 10^{6}$ & $0.596 \cdot 10^{6}$ & 4.1 \\
\hline 45 & $0.516 \cdot 10^{6}$ & $0.612 \cdot 10^{6}$ & 3 \\
\hline 66 & $0.688 \cdot 10^{6}$ & $0.625 \cdot 10^{6}$ & 2.05 \\
\hline 132 & $1.971 \cdot 10^{6}$ & $0.209 \cdot 10^{6}$ & 1.66 \\
\hline 220 & $3.181 \cdot 10^{6}$ & $0.11 \cdot 10^{6}$ & 1.16 \\
\hline 275 & $4.181 \cdot 10^{6}$ & $0.07 \cdot 10^{6}$ & 0.66 \\
\hline
\end{tabular}

\section{ACKNOWLEDGMENT}

This research has received funding from the Baltic InteGrid Project (http://www.baltic-integrid.eu/).

\section{REFERENCES}

[1] GWEC, "Global Wind Report. Annual Market Update 2017," Tech. Rep., 2017. [Online]. Available: http://gwec.net/publications/globalwind-report-2/.[Accessed Oct 29, 2018]

[2] X. Sun, D. Huang, and G. Wu, "The current state of offshore wind energy technology development," Energy, vol. 41, no. 1, pp. 298-312, 2012.

[3] ReNEWS, "Rampion suffers cable fault," 2017. [Online]. Available: http://renews.biz/105889/rampion-suffers-cable-fault/.[Accessed Oct 29, 2018]

[4] CIGRÉ, "Current Ratings of Cables for Cyclic and Emergency Loads. Part 1. Cyclic Ratings (Load Factor Less Than 100\%) and Response to a Step Function," Tech. Rep. 24, 1976.

[5] IEC, "IEC-60287-1: Electric cables - Calculation of the current rating," Tech. Rep., 2014. [Online]. Available: https://www.evs.ee/products/iec60287-1-1-2006.[Accessed April 15, 2019]

[6] —, "IEC-60853-2: - Calculation of the cyclic and emergency current rating of cables," Tech. Rep., 2008. 
[7] CIGRÉ: Working Group B1.40, "Offshore Generation Cable Connections," Tech. Rep. 1, 2015.

[8] V. K. Agarwal, H. M. Banford, B. S. Bernstein, E. L. Brancato, R. A. Fouracre, G. C. Montanari, J. L. Parpal, J. N. Seguin, D. M. Ryder, and J. Tanaka, "The Mysteries of Multifactor Ageing," IEEE Electrical Insulation Magazine, vol. 11, no. 3, pp. 37-43, 1995.

[9] L. Colla and M. Marelli, "Dynamic Rating of Submarine Cables . Application To Offshore Windfarms," in European Wind Energy Association (EWEA) Offshore 2013 Conference, 2013.

[10] G. J. Anders, A. Napieralski, and Z. Kulesza, "Calculation of the internal thermal resistance and ampacity of 3-core screened cables with fillers," IEEE Transactions on Power Delivery, vol. 14, no. 3, pp. 729-733, 1999.

[11] D. Chatzipetros and J. A. Pilgrim, "Review of the Accuracy of Single Core Equivalent Thermal Model for Offshore Wind Farm Cables," IEEE Transactions on Power Delivery, vol. 33, no. 4, pp. 1-1, 2017.

[12] C. Wolter, H. Klinge Jacobsen, G. Rogdakis, L. Zeni, and N. A Cutululis, "Overplanting in Offshore Wind Power Plants in Different Regulatory Regimes," 15th Wind Integration Workshop, pp. 1-9, 2016.

[13] M. A. H. Colin and J. A. Pilgrim, "Offshore Cable Optimization by Probabilistic Thermal Risk Estimation," in IEEE International Conference on Probabilistic Methods Applied to Power Systems (PMAPS). IEEE, 2018, pp. 1-6.

[14] S. Catmull, R. D. Chippendale, J. A. Pilgrim, G. Hutton, and P. Cangy, "Cyclic Load Profiles for Offshore Wind Farm Cable Rating," IEEE Transactions on Power Delivery, vol. 31, no. 3, pp. 1242-1250, 2016.

[15] R. Chippendale, J. Pilgrim, A. Kazerooni, and D. Ruthven, "Cyclic rating of wind farm cable connections," CIRED - Open Access Proceedings Journal, vol. 2017, no. 1, pp. 91-95, 2017.

[16] T. Kvarts, "Systematic Description of Dynamic Load for Cables for Offshore Wind Farms. Method and Experience," CIGRÉ, pp. 1-13, 2016.

[17] S. Lundberg, "Configuration study of large wind parks," Ph.D. dissertation, Chalmers University of Technology, 2003.

[18] P. Hou, W. Hu, C. Chen, and Z. Chen, "Optimisation of offshore wind farm cable connection layout considering levelised production cost using dynamic minimum spanning tree algorithm," IET Renewable Power Generation, vol. 10, no. 2, pp. 175-183, 2016.

[19] J. J. Grainger and W. D. J. Stevenson, Power System Analysis, 2nd ed. McGraw-Hill Education, 1994.

[20] J.-A. Pérez-Rúa, K. Das, and N. A. Cutululis, "Lifetime estimation and performance evaluation for offshore wind farms transmission cables," in Paper presented at 15th IET international conference on AC and DC Power Transmission, Coventry, United Kingdom, 2019, pp. 1-6.

[21] R. S. Olsen, J. Holboll, and U. S. Gudmundsdottir, "Dynamic Temperature Estimation and Real Time Emergency Rating of Transmission Cables," IEEE Power and Energy Society General Meeting, pp. 1-8, 2012.

[22] R. S. Olsen, G. J. Anders, J. Holboell, and U. S. Gudmundsdottir, "Modelling of Dynamic Transmission Cable Temperature Considering Soil-Specific Heat, Thermal Resistivity, and Precipitation," IEEE Transactions on Power Delivery, vol. 28, no. 3, pp. 1909-1917, 2013.

[23] L. A. Escobar and W. Q. Meeker, "A Review of Accelerated Test Models," Statistical Science, vol. 21, no. 4, pp. 552-577, 2006. [Online]. Available: http://projecteuclid.org/euclid.ss/1177334529.[Accessed Oct 29, 2018]

[24] G. Mazzanti, "The Combination of Electro-thermal Stress, Load Cycling and Thermal Transients and its Effects on the Life of High Voltage ac Cables," IEEE Transactions on Dielectrics and Electrical Insulation, vol. 16, no. 4, pp. 1168-1179, 2009.

[25] G. Mazzanti and G. C. Montanari, "A Comparison between XLPE and EPR as Insulating Materials for HV Cables," IEEE Transactions on Power Delivery, vol. 12, no. 1, pp. 15-26, 1997.

[26] W. Hauschild and W. Mosch, Statistical Techniques for High-Voltage Engineering, 1992.

[27] M. Marzinotto and G. Mazzanti, "Merging the electro-thermal life model for power cables with the statistical volume enlargement law," 2014 IEEE Conference on Electrical Insulation and Dielectric Phenomena, CEIDP 2014, no. 3, pp. 502-505, 2014.

[28] M. Miner, "Cumulative fatigue damage," Journal of Applied Mechanics, vol. 12, no. 3, pp. A159-A164, 1945.

[29] H. Brakelmann, "Loss Determination for Long Three-Phase HighVoltage Submarine Cables," European Transactions on Electrical Power, vol. 13, no. 3, pp. 193-197, 2003.

[30] ABB, "XLPE Submarine Cable Systems Attachment to XLPE Land Cable Systems - User's Guide," 2018. [Online]. Available: new.abb.com/docs/default-source/ewea.../xlpesubmarine-cable-systems-2gm5007.pdf.[Accessed Oct 29, 2018]
[31] HELCOM, “Our Baltic Sea," 2017. [Online]. Available: http://stateofthebalticsea.helcom.fi/in-brief/our-baltic-sea/. [Accessed Oct 29, 2018]

[32] P. Sørensen, N. A. Cutululis, A. Vigueras-Rodríguez, L. E. Jensen, J. Hjerrild, M. H. Donovan, and H. Madsen, "Power Fluctuations From Large Wind Farms," IEEE Transactions on Power Systems, vol. 22, no. 3, pp. 958-965, 2007.

[33] M. Koivisto, K. Das, F. Guo, P. Sørensen, E. Nuño Martinez, N. A. Cutululis, and P. Maule, "Using time series simulation tool for assessing the effects of variable renewable energy generation on power and energy systems," WIREs Energy and Environment, no. June, pp. 1-15, 2018.

[34] G. Mazzanti, "Analysis of the Combined Effects of Load Cycling, Thermal Transients, and Electrothermal Stress on Life Expectancy of High-Voltage AC Cables," IEEE Transactions on Power Delivery, vol. 22, no. 4, pp. 2000-2009, 2007. 